\title{
ENTRE UTOPÍA Y REALIDAD: Historia de LA UNIÓN de Ejidos de la Selva
}

\author{
Marco A. Estrada Saavedra
}

Para Gemma van der Haar, de espiritu libre.

¡Hay tan poca gente que ame los paisajes que no existen!... Saber que seguirá existiendo el mismo mundo mañana -¡Cómo nos desazona!...

Fernando Pessoa

\section{Introducción}

$\mathrm{E}$ 1 presente artículo, ${ }^{1}$ es una contribución al conocimiento de la historia política tojolabal contemporánea, pretende profundizar en nuestra comprensión del movimiento campesino chiapaneco en el siglo xx, cuya historia, aún está por ser escrita. ${ }^{2}$ En particular, doy cuenta del proceso organizativo que se ha dado en la Unión de Ejidos de la Selva, uEs, del municipio de Las Margaritas (mapa en Anexo). Para empezar expongo de manera sucinta el marco teórico subyacente a este estudio; enseguida abordo las primeras experiencias de organización colectiva de los tojolabales modernos, con énfasis en cómo se forman ejidos mediante la afectación de las fincas agropecuarias y la colonización de cañadas en la Selva Lacandona. El acoplamiento estructural entre la diócesis de San Cristóbal y las comunidades ejidales católico-liberacionistas, sumado a la politización de los habitantes de la región a través de la formación de diferentes uniones ejidales; por último, me ocupo

Marco A. Estrada Saavedra, El Colegio de México. exclusivamente de la historia de la Unión de Ejidos de la Selva, 1970-2004.

En términos teóricos, concibo a las organizaciones campesinas como actores colectivos, cuyas movilizaciones de protesta son construidas desde el mundo de vida. ${ }^{3}$ La constitución de un actor colectivo supone un proceso complejo y conflictivo de coordinación de interacciones con miras a intereses comunes mediante la movilización organizada de recursos y habilidades estratégicas.

Pormedio de la organización se construyen, articulan, restringen y orientan las acciones e intereses generales. El resultado de todo lo anterior no es simplemente una coordinación de interacciones sociales, sino además una resignificación de las relaciones sociales cotidianas y, con ello, la redistribución de poder, recursos y oportunidades entre los actores sociales involucrados, quienes, en medio del proceso de organización y participación política, perciben, comprenden y definen de nuevas maneras el origen de sus problemas, "necesidades sociales", el contexto de conflicto, oponentes - ya sean otros actores o instituciones 
políticas - , con los cuales habrán de enfrentarse para ver resueltas sus demandas sociales y satisfacer los intereses generales de la movilización de protesta. Paralelamente, los actores sociales recuperan los recursos simbólicos constituyentes de su mundo de vida. En otras palabras, se apropian activamente, pero de manera resignificada, de las identidades sociales compartidas, la memoria y las experiencias colectivas anteriores de lucha, dando así un nuevo sentido al espacio social de las interacciones cotidianas, las motivaciones particulares de participación y, por último, pero no por ello menos importante, a la imagen personal de sí mismos. Todo ello, como conjunto supone una reactivación de las redes sociales de pertenencia y de la solidaridad social, que cohesionan a los actores sociales y los involucran en la participación en el conflicto.

Ahora bien, las imágenes ingenuas que generan conceptos como "movimiento social" y "actor colectivo" evocan la idea de que éstos son "unidades": grupos fuertemente cohesionados sin hendiduras internas. Esta representación es entendible en el momento en que nos percatamos de nuestros atavismos al observar a los actores colectivos en la movilización pública en un "campo social de conflicto" entre oponentes, en donde las identidades de los antagonistas parecen bien definidas. Esta cohesión y unidad públicas no son sino sólo un efecto visual distorsionante, porque el actor colectivo, como constructo sociobistórico, supone una complejidad interna resultante de los conflictos internos entre sus grupos sociales que pugnan por determinar cursos de acción, objetivos, valores, normas, relaciones de poder, distribución de recursos materiales y simbólicos, significados y sentidos de la identidad y memorias sociales que organicen y orienten la participación de los actores sociales involucrados. Dicho con otras palabras, al interior del actor colectivo existe, entre las diferentes élites y las distintas fracciones de las bases sociales que lo componen, una lucha por definir y determinar hegemónicamente qué es dicho actor, qué persigue y cómo se ha de presentar en el conflicto público. Así entendidos, los actores colectivos no están construidos "de una vez y para siempre" ni acabados — salvo que desaparezcan definitivamente del campo social.

Las acciones colectivas son movilizaciones en las cuales los actores sociales individuales que las conforman comprometen su participación y cooperación para obtener bienes públicos o colectivos. De tal suerte, como acción organizada, no necesita de la participación universal de todos permanentemente, ni que todos los miembros, actuales o posibles, se dispongan a prestar su cooperación en las mismas actividades. En efecto, la "élite" dirigente de la organización del actor colectivo se encarga de distribuir esfuerzos y recursos en áreas diversas con vistas a contribuir al mejoramiento del resultado final de la movilización y organización colectivas. Además, funge como catalizador al convenir la distribución de costos y beneficios y alentar la participación de sus "bases", logrando con ello una organización más o menos estable como medio para obtener bienes colectivos, promoviendo acuerdos que suavicen intereses encontrados y hagan posible, o al menos tolerable, su compatibilidad para generar permanentemente movilizaciones colectivas de protesta.

\section{Lucha por la tierra y formación de los ejidos}

En la región de Comitán y Las Margaritas, la historia política moderna de los tojolabales se inicia alrededor de 1933 con el desmantelamiento del sistema de fincas mediante el reparto agrario y la reconversión ganadera de los restos de las fincas agrícolas. La lucha por la formación de ejidos — primero a expensas de las fincas afectadas y después mediante la colonización de los terrenos nacionales de la Selva Lacandona - supuso para los tojolabales un proceso de aprendizaje colectivo de la gramática de la organización política. ${ }^{4}$ En efecto, en la construcción de nuevas comunidades campesinas, 
los tojolabales actuaron motivados por un anhelo de autonomía que exigía de ellos la cooperación voluntaria más allá del ámbito doméstico para afrontar los riesgos y costos de su empresa y disfrutar, del mismo modo, los beneficios de la formación, organización y gobierno de sus propios ejidos (sobre el tema, véase Estrada, 2003).

Aunque la lucha por la dotación ejidal fue colectiva, rara vez hubo cooperación entre los campesinos de las diferentes colonias agrícolas para organizarse en contra de los finqueros y la burocracia de la reforma agraria. En realidad cada núcleo de solicitantes de tierras actuaba por su cuenta y consideraba a los demás posibles competidores por un recurso escaso. De esta manera, la formación primero, y el funcionamiento después, de los ejidos tuvieron lugar en un contexto de solidaridad restringida entre los campesinos. Así, para los tojolabales, el ejido se convirtió en una pequeña república independiente.

Dentro del marco legal de la Ley Agraria las colonias agrícolas constituidas a través de la dotación de tierras ensayaron estructuras sociales de autoridad, organización y representación que probablemente cohesionarían a las nuevas comunidades y definirían sus orientaciones colectivas de acción, ya que la desaparición del orden de dominación finquero dejó, para la población tojolabal ex acasillada, un "vacuum institucional" (Van der Haar, 2001: 112) que los campesinos solicitantes de tierras se vieron obligados a llenar para reordenar su vida social. De esta manera, la lucha por la obtención de tierras ejidales fue el principio generador de una rudimentaria organización social posfinquera llamada comité agrario mixto, constituida por el grupo de los peticionarios y sus familias. Esto supuso la coordinación de actividades y responsabilidades, la movilización de su acervo de conocimientos y recursos materiales, así como la utilización de redes sociales familiares y vecinales, la generación de confianza mutua, solidaridad, y la formación de una nueva identidad social; todo ello con el fin de enfrentar las incertidumbres, novedades y dificultades de la empresa para culminar en una vida más allá del "baldío".

El ejido es una forma de organización de la vida social rural que redefine la estructura de poder y autoridad de la comunidad. La Asamblea es la depositaria de la autoridad y el poder comunitarios. Su órgano ejecutivo es el "comisariado ejidal". A través de la asamblea "los ejidatarios organizan y ejercen control sobre los miembros individuales de la comunidad". En ella, los ejidatarios definen "en qué consiste el derecho de cada uno, así como las condiciones de membresía, coordinación de tareas y aplicación de sanciones". Su autoridad no sólo se extiende sobre cuestiones agrarias, también sobre todo tipo de asuntos colectivos y de interés general. Así influye sobre los ejidatarios y el conjunto de miembros de la comunidad; por esta razón es " de facto, el gobiemo local" de la comunidad (Van der Haar, 2001: 133).

La participación en el proceso de deliberación y toma de decisiones en la asamblea, se encuentra restringida sólo a los miembros de la comunidad, particularmente a los ejidatarios, pues, como los acuerdos son vinculantes universalmente tienen efectos sobre el conjunto de la comunidad, que serían potencialmente negativos si interviniese alguien extraño a la misma con un interés contrario al colectivo ( $c f r$. Van der Haar, 2001: 138). En este sentido, la organización ejidal representa un ámbito de protección frente al mundo externo similar a un bastión de la autonomía intracomunitaria. Efectivamente, en reacción al poder político municipal, del que han estado excluidos los indígenas hasta hace apenas algunos años, los tojolabales "ejercen un estricto control al interior de su comunidad” (Ruz, 1990: 191). De esta manera, las colonias agrarias son oasis de autonomía en donde se recrea el mundo y la vida social cotidiana local sin mayor interferencia e intromisión de extraños. ${ }^{5}$ La autonomía hace referencia, entonces, a la (re)producción de la vida cotidiana en la que sólo los miembros de la comunidad discuten y dirimen 
conflictos comunitarios, riñas familiares y vecinales, incluyendo, también, la participación en la esfera religiosa, en las uniones ejidales, en programas gubernamentales o en proyectos de ONG.

En fin, para los tojolabales eran evidentes los beneficios de la autonomía comunitaria interna que gozaban desde la fundación de sus ejidos; sin embargo, esa autonomía tenía un rostro problemático: el aislamiento del resto de la vida social tojolabal regional - exceptuando, por supuesto, las verbenas religiosas ${ }^{6}$ y el intercambio comercial en Comitán y Las Margaritas - En realidad, carecían de una conciencia de intereses sociales y políticos comunes, también de los medios para solucionar problemas compartidos. Sin contar la cooperación excepcional en los momentos de desastres naturales y de malas cosechas, el aislamiento de los ejidos era, en realidad, una auténtica indiferencia hacia la suerte de sus compañeros campesinos que vivían más allá de los límites de sus ejidos.

\section{La Palabra de Dios}

Esta incomunicación entre ejidos empezó a desaparecer sólo hasta la aparición de los agentes de pastoral "liberacionistas" de la diócesis de San Cristóbal en las postrimerías de la segunda mitad de la década de mil novecientos sesenta.

Justo en el periodo "liberacionista" de la diócesis, entre 1969-1999, en el mundo indígena-campesino se configura una "catequesis de la encarnación" bajo la concepción de la Teología de la liberación. Toda la vida de la comunidad social, económica, política y cultural se revela como el "lugar teológico" por excelencia. Los catequistas indígenas se vuelcan a la participación activa y crítica y se convierten en "portavoces de la reflexión de la comunidad... La palabra de Dios se va reflexionando en el seno de las comunidades a partir de los acontecimientos y situaciones vivenciales y son los catequistas los 'recolectores de la cosecha del pensamiento comunitario' " (Iribarren, 2003: 56). De tal suerte, las comunidades indígenas reaniman su vida colectiva a través de las ceremonias religiosas y la reflexión bíblica. Bajo la luz del Evangelio, se descubren como personas con "dignidad" por ser "hijos de Dios", portadoras de derechos exigibles y con una cultura particular valiosa. En otros términos, las comunidades comienzan a reconocerse como un actor colectivo que ostenta la capacidad de influir en su propio destino.

A través de la intensa labor colectiva catequística se empezó a construir entre las comunidades tojolabales una civitas christi. Ésta implicaba la transformación radical de la vida individual y colectiva. La "salvación" del alma colectiva comunitaria no tenía que esperar el "juicio final", pues podía materializar el "Reino de Dios aquí y ahora". Para los auténticos cristianos, resucitados en la fe, la tierra colonizada que habían habitado fue reconocida y resignificada como la "tierra prometida", en ella realizarían su tan anhelada "liberación". Así, la civitas christi suponía una reestructuración profunda de la vida social: por un lado se inicia un proceso de recuperación, reevaluación y reinvención positiva de lo tojolabal; por el otro, se requería, al unísono, que las necesidades espirituales y materiales de la comunidad fuesen satisfechas. En este sentido se configura un proceso de conscientización y de (re)formación de una identidad colectiva, así como de organización mediante la cual se asumiera de modo colectivo la solución de problemas que los aquejaban desde la fundación de las colonias y ejidos. El eje articulador de los dos momentos sería la revitalización y resignificación de su fe católica teñida con tintes liberacionistas. Las comunidades tojolabales empezaban a encontrar la "propia voz" entre los acordes de la melodía de la teología de la liberación. Así, organizaron sus propias cooperativas de producción y consumo, entre otras, para asumir, de manera autónoma y ante el desinterés y la corrupción 
gubernamentales, la responsabilidad por su propia suerte (sobre el tema, consúltese Estrada, 2004). ${ }^{7}$

Pero los cambios en la estructura y organización de la comunidad no sólo se dan internamente, pues la labor pastoral también produjo una redefinición de las relaciones intercomunitarias en las cañadas tojolabales. Con su trabajo, los equipos de pastoral y los catequistas tenderían una red que comunicaría y vincularía a las distintas comunidades de la región y a éstas con la estructura diocesana. De manera semejante a sus contrapartes en otras zonas pastorales, la Misión de Guadalupe y La Castalia — las dos escuelas de formación de catequistas en el sureste de la diócesisse convertirían en centros de intercambio de información, experiencias, ideas, proyectos y recursos, que a la larga permitiría no sólo estrechar lazos entre los diferentes grupos pastorales, sino, sobre todo, promover toda la organización pastoral en equipo de manera más institucionalizada y funcional. Además, la vinculación interpastoral resultó, a la larga, en un enlazamiento de las comunidades indígenas, tanto en las zonas de colonización como con el resto de las regiones indígenas del estado. Las escuelas de catequistas no eran, únicamente, centros de formación espiritual, también lo eran en oficios, así como de conscientización política, como se manifiesta en el siguiente testimonio. "En los cursos en La Castalia aprendimos distintas cosas como estudiar la Biblia, los primeros auxilios, la carpintería, la mecánica, la sastrería, las matemáticas y, también, la ley agraria, cómo formar uniones ejidales, hacer una cooperativa, organizar el trabajo colectivo, gestionar escuelas o caminos y resolver problemas comunitarios" (entrevista con Caralampio Cruz, catequista y líder de Tierra y Libertad, 29 de diciembre de 2004). De tal suerte que el trabajo de los catequistas en sus respectivas comunidades creaba nuevos fundamentos de integración y solidaridad sociales, así como la toma de conciencia de las realidades y problemas comunes compartidos.

\section{Del Reino de Dios al de la política}

Gracias a este proceso de ilustración y crítica colectivos, los catequistas empezaron a observar que la "palabra de Dios" por sí sola era insuficiente para superar los graves problemas cotidianos que aquejaban a las comunidades. La organización de la civitas christi había permitido estrechar los lazos intracomunitarios y fomentar entre sus miembros la creencia de que, como hijos de Dios, eran personas dignas y libres que merecían gozar y ejercer sus derechos. "Pero ¿cómo hacerlo?", se preguntaban los catequistas cuando la vida nueva suponía abandonar enfermedad, pobreza, desigualdad, ignorancia, incomunicación e injusticia en las que existían. Por eso, inspirados en su particular exégesis de la Biblia, buscaron respuestas en fuentes profanas para que la salvación de sus "almas" acompañara a la de sus "cuerpos". Sus pesquisas los condujeron a partidos políticos de oposición, activistas de la izquierda social, y hasta a los mecanismos corporativos del partido oficial. Fue gracias al segundo de estos grupos que los catequistas comprendieron que su "liberación" dependía de su propia voluntad y organización. De esta forma, mientras que su vocación de servicio la descubrieron con plena conciencia en la catequesis, sin embargo; su compromiso sólo adquirió un rostro más terrenal y práctico gracias a la orientación organizativa y política de los "asesores" y "brigadistas", es decir, de los grupos de activistas políticos de la izquierda social que pensaban que la "revolución" sólo era posible conscientizando y organizando directamente a las "masas". Estos activistas vieron en los colonizadores tojolabales de la selva el potencial revolucionario del "pueblo" campesino un pueblo que no sólo ya había adquirido por sí mismo una forma rudimentaria de organización social a través de la fundación de colonias y ejidos, sino que, además, gozaba de identidad y solidaridad sociales que facilitaban, en cierta medida, la cooperación para las tareas colectivas que implicaba la 
construcción y funcionamiento de organizaciones campesinas. Por su parte, los tojolabales veían en los asesores y activistas políticos agentes comprometidos que los apoyaban en su "liberación".

De tal suerte, la comunidad republicana de masas se configuró en las cañadas tojolabales cuando, primero, se extendieron y formalizaron regionalmente las prácticas de convivencia y solidaridad típicas de la civitas christiy, segundo, el sentido de las relaciones interejidales ya no se estructuró ni orientó de manera primordial de acuerdo con el ideal de la salvación colectiva intramundana mediante una reforma radical de la vida cotidiana comunitaria, sino en razón de la construcción de un "poder popular" autogestivo dado a través de la consecución, organizada colectivamente, de proyectos sociales y agropecuarios. En otras palabras, la comunidad republicana de masas politizó la civitas christi haciendo real la liberación del alma colectiva a través del cuidado y bienestar del cuerpo de las masas. Esta transformación se fundamentó en el aumento de la participación de los miembros de las comunidades ejidales en los asuntos y tareas colectivos, con lo que se aprendieron y desarrollaron capacidades de entendimiento y cooperación interejidales a través de la negociación de intereses comunes. Así, la tierraprometida de las cañadas tojolabales fue transformada por las organizaciones campesinas en el territorio de la confederación de las repúblicas elementales ejidales (sobre el tema véase Estrada, 2005).

De la Iglesia, los campesinos habían aprendido que tenían derechos, pero desconocían, en realidad, cómo hacerlos efectivos y qué se podía lograr con ellos. Los candentes debates del Congreso Indígena de 1974 en San Cristóbal de Las Casas les ofrecieron una idea concreta y práctica del significado y contenido de esos derechos: salud, educación, comercio y producción. Dado que la preparación y organización material del Congreso había sido responsabilidad de los activistas políticos por encargo expreso del obispo de San
Cristóbal, no fue entonces casualidad que los primeros proyectos de las organizaciones campesinas que se formaron después en la región asumieran estas demandas en su lucha. ${ }^{8}$

De origen universitario, principalmente de centros de estudios superiores como la Universidad Autónoma Chapingo, la Universidad Autónoma de Nuevo León y la Universidad Autónoma de México, aunado a la experiencia en la actividad política izquierdista, los asesores y brigadistas de las organizaciones campesinas operaban como ideólogos, promotores de proyectos productivos y sociales, y consultores especializados. En tanto ideólogos ofrecían a las organizaciones y comunidades campesinas un proyecto político que consistía en la formación de un poder popular autogestivo, algo muy parecido, creerían los tojolabales, al "anhelo de autonomía" de los indígenas liberados de la finca. Éste era el principio ideológico que orientaba, justificaba y jerarquizaba todo plan de acción posterior. Como promotores, los asesores proponían a los indígenas la realización de proyectos sociales creación de escuelas o centros de salud - y productivos: comercialización de café, créditos para la explotación ganadera. Por último, como consultores especializados los asesores ofrecían su conocimiento experto a las organizaciones en materias como agronomía, asesoría legal, negociación política, relaciones públicas o manejo de instrumentos financieros. Además de las tres funciones que cumplían para las organizaciones campesinas, los asesores ponían a disposición de éstas un rico abanico de contactos con instituciones públicas, universidades, "oeneges", así como con funcionarios públicos, que los conectaban en una red de cooperación que podía facilitar la consecución de sus objetivos.

Para los asesores y activistas sociales de tendencia ideológica maoísta que cooperaron decisivamente para construir las organizaciones campesinas en las cañadas tojolabales, en particular, y en la Selva Lacandona, en general, el objetivo de su quehacer político directo con 
las "masas" populares consistía en "crear un vínculo entre organizaciones campesinas, sindicatos y grupos populares [para formar] un gran movimiento de masas [con el fin de] democratizar el país tomado el poder por la vía legal". Ciertamente no descartaban de antemano la vía armada, sin embargo, a diferencia de la Liga 23 de Septiembre y sus estrategias de guerrilla urbana o la de Lucio Cabañas y su guerrilla rural, por ejemplo, los maoístas pensaban que la opción por el recurso de las armas "no tenía que ser una decisión nuestra, sino, en última instancia, una decisión de las masas" (entrevista con René Gómez, ex asesor de la ARIC-Unión de Uniones y de la Unión de Ejidos de la Selva, 11 de agosto de 2003). Al respecto abunda Tere García, ex asesora de Tierra y Libertad: "La Unión del Pueblo era una organización clandestina con un planteamiento revolucionario para tomar el poder a través de generar bases sociales de apoyo. La idea era que la gente se apropiara de las formas de organización a través de la 'concientización de las masas' en un proceso lento que llamábamos 'guerra popular prolongada'. Pensábamos que el trabajo político se tenía que hacer en el campo por las particularidades de México, pues era imposible seguir el marxismo-leninismo en la cuestión de que eran los obreros los que tenían que constituirse como la vanguardia revolucionaria. Creíamos que teníamos que llevar la lucha popular prolongada de la periferia al centro, del campo a la ciudad. Nuestros esfuerzos se encaminaron a Chiapas, porque el Comité Central vio que en el sureste del país había muchas mejores condiciones para crear esas bases sociales, ya que existían condiciones geográficas, de marginación, grupos con mucha sensibilidad y, una cosa importante que no veíamos claro entonces pero que ahora explica muchas cosas, no había Estado. Para ganar [la] confianza [de los campesinos], los activistas de la Unión del Pueblo llegábamos con la gente a trabajar buscando estar inmersos en sus problemas y ayudando a resolverlos" (entrevista, 21 de octubre de 2004).
Los activistas políticos sabían, de antemano, que el trabajo de conscientización y organización de las masas no era fácil, pues pretendían trascender la "cultura caciquil" de las organizaciones populares: “Lo que queríamos era una organización definitivamente democrática, donde las decisiones se tomaran por la mayoría" (entrevista con René Gómez, 11 de agosto de 2003). De tal suerte, se modificaría la cultura y actitud pasiva imperante en las comunidades con el fin de fomentar, mediante mayor transparencia y fiscalización en el ejercicio del poder, la participación más activa en los asuntos concernientes a todos.

\section{Tierra y Libertad: primer intento de organización campesina en la región}

Durante el Congreso Indígena de 1974 surgieron ideas y propuestas en torno a la organización de los indígenas para encarar sus problemas. De allí nació el interés de crear uniones ejidales. Los activistas políticos maoístas se encargaron del diseño y mecanismo de las mismas con el consenso y cooperación de los campesinos.?

La Unión de Ejidos de la Selva, UEs, nace formalmente en junio de 1979. En su constitución como organización campesina confluyen, como hemos mencionado, dos procesos: el trabajo pastoral de la diócesis de San Cristóbal y la labor de activistas políticos de línea maoísta. En particular, las comunidades que conformarían UEs habían tenido previas experiencias "formales" de organización, principalmente en la Unión de Ejidos Tierra y Libertad y en la Cooperativa Belisario Domínguez, una organización para la comercialización de café, así como experiencias "informales" como la de su participación en la Unión de Ejidos Quiptic ta Lecubtesel, alrededor de 1974: "era una relación de solidaridad que formaba parte orgánica de una misma organización de hecho, pero no de derecho" (entrevista con Ing. José Juárez, asesor en la ues, 9 de agosto de 2003). Así, la conjunción de 
las voluntades de los agentes de pastoral, los activistas políticos maoístas y los campesinos tojolabales formarían la Unión de Ejidos de la Selva.

$\mathrm{El}$ antecedente organizativo directo fue la Unión Ejidal Tierra y Libertad, una de las varias uniones ejidales que formarían los tojolabales católicos con el apoyo decidido de los activistas maoístas en la década de 1970. Tierra y Libertad surge, a su vez, del conflicto que originó, en 1979, el encarcelamiento de dos ejidatarios en la cañada La Soledad por motivo de la tala "ilegal" de árboles. Ante la falta de capacidad efectiva para exigir al gobierno municipal su liberación, los campesinos se acercaron a Lucha Campesina, unión ejidal que había nacido unos años antes en la cañada tojolabal del municipio de Comitán. La dirigencia de Lucha Campesina ofreció ayudar en la excarcelación de los campesinos presos si las comunidades movilizadas para este propósito se incorporaban a la unión ejidal. Por eso "de la noche a la mañana nos hicimos parte de la organización, y como en tres meses salieron libres nuestros compañeros por la fuerza de la organización y la plebe", cuentan los antiguos socios de Lucha Campesina del ejido Tabasco. Su participación en la unión ejidal fue, no obstante, breve. Después de un año, durante el cual los catequistas de las comunidades de la cañada La Soledad asistían a La Castalia para su formación religiosa donde también se les enseñó "cómo formar una unión ejidal", según su testimonio, decidieron, entonces, “organizar Tierra y Libertad para que nos respeten los gobernantes. Nuestra unión fue el [producto del] trabajo de nuestros catequistas y comisariados ejidales. Así reunimos, por acuerdo, a [los ejidos] Tabasco, Chiapas, Belisario Domínguez, Aquiles Serdán, Rafael Ramírez, Mexiquito, Buenavista Pachán, Cruz del Rosario, y, después, entraron algunas comunidades de allí abajo [es decir, de la región de la Selva]. Pero no dejamos Lucha Campesina por pleito, sino por el problema de la 'caminada', pues la cañada tojolabal está algo retirada de la [cañada] La Soledad [en donde se encuentra el conjunto de comunidades que forma Tierra y Libertad]. Dijimos que había necesidad de pelear también esta ruta MargaritasNuevo Momón [a diferencia de la ruta de transporte Comitán-Altamirano, donde se ubican la cañada tojolabal y la base social de Lucha Campesina], porque los propietarios de transportes nos maltrataban mucho en esos tiempos" (entrevista colectiva en ejido Tabasco, 29 de diciembre de 2004).

En el marco del objetivo de los activistas maoístas de crear un "poder popular" a través de la "concientización y organización de las masas", se encontraba la estrategia de constituir uniones ejidales regionales de mediano tamaño en lugar de grandes centrales campesinas, para incrementar la identificación y participación de sus socios en la organización campesina. "[En 1978] los que estábamos trabajando [como brigadistas] en lo que fue la primera unión de ejidos [formada por este grupo en la selva de Ocosingo], la Quiptic, nos planteamos separarnos para construir distintas organizaciones sociales [en otras regiones]. En este contexto es como empezamos a ver en la zona de Las Margaritas la posibilidad de construir Tierra y Libertad. En esa época se crearon diferentes Uniones: Lucha Campesina,${ }^{10}$ Relámpagos de Agosto, Ejidos de la Selva, y Tierra y Libertad. Digamos que éstas, más la Quiptic, son como las organizaciones madres que nos permitieron, con éxito, ser aceptados por los campesinos y la Iglesia. Nosotros en Política Popular decíamos que si creábamos organizaciones muy grandes, a la gente se le haría más difícil apropiarse de sus Uniones. Por eso, en nuestra lógica era mucho más fácil crear organizaciones pequeñas que pudieran ser controladas por los campesinos" (entrevista con Tere García, octubre de 2004).

Para los campesinos de la región el objetivo principal de Tierra y Libertad era claro: lograr la construcción de una carretera y conseguir transporte. 
A B I E R T A

"Tierra y Libertad era una organización grande a la que pertenecían comunidades desde Mexiquito hasta Vicente Guerrero. Nosotros pensamos que la ruta de transporte debía ir de Las Margaritas a San Quintín. Así, todos nosotros buscamos trabajar juntos y hacíamos reuniones en Cruz del Rosario, Vicente Guerrero y hasta Santa Lucía" (entrevista colectiva en el ejido Buenavista Pachán con miembros de la CIOAC-Unidos con la Nueva Fuerza Tojolabal, anteriormente miembros de Tierra y Libertad, 21 de diciembre de 2004). $\mathrm{Al}$ respecto, los socios de UES en Cruz del Rosario rememoran: "La carretera se empezó a gestionar en 1969; entonces recibimos mucho apoyo del movimiento magisterial, de las secciones 7 y 40 de maestros, y de las organizaciones de Margaritas y Ocosingo. Hicimos una marcha pidiendo la carretera, porque en aquel tiempo estábamos organizados con LiconsaConasupo. Tuvimos contactos con ellos y teníamos tres tiendas [de Liconsa] en Guadalupe Tepeyac, Vicente Guerrero y Rizo de Oro. En un avión Islander metíamos la mercancía a las comunidades. Así, en cada una de esas comunidades fuimos a arreglar la pista y a hacer una casa [es decir, un almacén]; pero, como organización, vimos que era necesario tener una carretera, porque esos apoyos [de Liconsa] iban a acabarse [algún día] —eran puros apoyos que daban para tener una tienda cerca y no tener que ir a Las Margaritas. Entonces, se empezaron a conjuntar los problemas de [las comunidades selváticas en] Ocosingo y Las Margaritas y decidimos hacer una marcha [a Tuxtla Gutiérrez] para la construcción de la carretera Margaritas-San Quintín-Ocosingo, en la región de Amador [Hernández], en donde no había caminos y así se unieran esos caminos de los municipios. Así fue como [más tarde] nos resolvieron el problema del camino, aunque entonces sólo se dio un tramo: de Chiapas a Nuevo Momón" (entrevista colectiva con socios de UES en Cruz del Rosario, 8 de agosto de 2004).

\section{Crisis de Tierra y Libertad y fundación de la Unión de Ejidos de la Selva}

Los problemas y las diferencias internas en la unión ejidal no se hicieron esperar. El primer obstáculo a vencer era hacerse del dinero suficiente para adquirir un camión de transporte de personas y mercancías que paliara la incomunicación en la que se encontraban los pobladores de esta región. "A principios de los ochenta los compañeros comenzamos a cooperar para el enganche de un autobús con capacidad para 40 pasajeros. Y se logró dar un enganche gracias al señor Carlos Lenkersdorf. Fue un 20 de abril que llegó el autobús hasta Buenavista Pachán" (entrevista colectiva con socios de Tierra y Libertad en ejido Tabasco, 29 de diciembre de 2004). El sabor a triunfo por la adquisición del automotor muy pronto se vio agriado, primero, por las disputas entre los ejidos asociados a Tierra y Libertad sobre la ruta que debería de seguir el camión y la distribución de los beneficios de la lucha y, segundo, por los conflictos ideológicos entre los asesores políticos de la unión ejidal sobre la concepción, el sentido y la estrategia de la lucha política. "Cuando se empieza a organizar la lucha por el trasporte", relata Genaro Jiménez, uno de los líderes de UEs, "se decía que iba a ser una lucha para los pobres, y, como era así, los que tuviéramos más [recursos], podíamos dar más, y los que tuviéramos menos, menos. La lucha consiguió el camino, que empezó a avanzar hasta Cruz del Rosario [en tanto que] ya casi iba la brecha hasta Vicente Guerrero. La idea [de la lucha] era, entonces, que, independientemente de la cantidad, todos los que cooperaban tenían derecho [a los beneficios de la lucha]. Y nosotros sí quisimos exigir que se nos respetara y que el camión llegara hasta nuestra comunidad para que podamos aprovechar la salida [es decir, la transportación de personas y bienes]. Pero allí empezaron los problemas, pues nos decían [a los de las comunidades que no eran socias de la Unión, pero que sí 
habían participado en el movimiento] que no podemos exigirles porque casi no habíamos cooperado. ‘No que la lucha era para los pobres? ¡A hora resulta que el que va a mandar es el que tiene más paga!', se dijo mucho entonces. Pero cuando de verdad arranca [surge] la división más seria fue cuando se empezaron a solicitar y ejecutar proyectos como el de CONASUPOLICONSA. [Gracias a él] se construyó un gran almacén en Vicente Guerrero que servía como centro distribuidor para el resto de las comunidades de la selva. A los compas de Tierra y Libertad no les gustó la gestión de este proyecto, pues decían que su lucha era social, por la tierra y el camino, y que no querían nada del gobierno, porque si [éste] empezaba a meter proyectos era como rendirse al gobierno. Ya no nos pudimos entender, porque nuestro delito fue, según ellos, haber agarrado esos proyectos. Se armó, entonces, la discusión, y ellos ya no quisieron seguir participando con nosotros. En ese momento, la misma comunidad de Cruz del Rosario se puso a discutir: ‘'nos quedamos o nos salimos [de Tierra y Libertad]?'. Y así sucedió en otras colonias: unos se quedaron y otros se salieron. Una gran parte se quedó con Tierra y Libertad y con uno de sus asesores, Carlos Lenkersdorf, un alemán que se los jaló. La otra parte se quedó con otro asesor que estaba en la región Selva, Ignacio Simón. $\mathrm{Y}$ así fue como empezamos a hacer la gestión para formar legalmente la Unión de Ejidos de la Selva" (entrevista con Genaro Jiménez, líder de UES, 9 de agosto de 2003).

En 1980 se consumó, entonces, la división campesina. Después de su ruptura con la Unión de Ejidos Tierra y Libertad, tres comunidades iniciaron la formación de "La Selva": Nuevo Momón, Cruz del Rosario y Montecristo. Posteriormente, la joven unión ejidal creció hacia el interior de la Selva Lacandona, porque allá se incorporaron Flor del Río, El Edén, San Isidro, Vicente Guerrero, San Carlos del Río, San Carlos
Veracruz, San Francisco El Naranjo, San Juan Bautista, Guadalupe Tepeyac, La Realidad Trinidad, Santa María Río Blanco, Río Corozal, Benito Juárez, San Marcos, Rizo de Oro, El Porvenir, Arroyo Nacimiento, San José Nueva Esperanza, entre algunas otras (entrevista con Genaro Jiménez, líder de UEs, 9 de agosto de 2003).

El proyecto original de UES contemplaba tres metas fundamentales: "tierra, camino y café", como dicen los mismos campesinos. Estos fines - que hay que entender dentro del marco estratégico de la lucha e ideología maoísta de los "pretextos y objetivos"tenían que ver con el "nivel" de desarrollo político de las comunidades. Como vimos en la sección anterior, el objetivo más compartido y deseado entre las comunidades de la región era la necesidad de la construcción de vías carreteras de comunicación; el segundo tenía que ver con la regularización de la tierra: falta de documentación agraria, procesos inconclusos de regularización bajo el régimen ejidal, problemas de definición de linderos; resultantes del burocratismo, la corrupción y el corporativismo político de los instituciones y agentes encargados de la tutela del agro mexicano. El tercer objetivo giraba en torno a la producción y comercialización de café. "Los tres ejes tenían diferentes niveles de intensidad, por lo que en determinadas situaciones cobraba alguno de ellos mayor relevancia que los otros" (entrevista con Ing. José Juárez, asesor en UEs, 9 de agosto de 2003). Años más tarde los campesinos recordarían la hazaña de la construcción de su propia unión ejidal con las siguientes palabras: "La lucha de nuestros padres es que no se han dejado vencer con los problemas que han encontrado ellos... Para organizarse encontraron muchos problemas; hasta tuvieron que ser amenazados por las autoridades municipales y estatales, [porque] no les gustaba que la gente se organice. El temor era que si la gente se organiza ya no va seguir engañada con la forma como nos tenían". ${ }^{11}$ 
La creación de "La Selva" había sido un paso difícil en la organización campesina tojolabal; sin embargo, no fue el último y ni siquiera el más arduo. Los problemas cotidianos y concretos de la unión ejidal fueron desplazando los más abstractos y lejanos como los de la formación de un poder popular que contribuyera a la revolución de las masas, como querían antaño los activistas políticos. En efecto, UES consiguió durante los siguientes años que cada uno de sus socios ejidales tuviera legalizada su situación agraria, por otro lado también adquirió camiones de carga. Después de una crisis de orientación ideológica en la que de nuevo los asesores políticos se dividieron, empezaron a plantearse "nuevos objetivos y ejes de acción" para reanimar la vida de la Unión, solucionando problemas sociales como el abasto, la salud comunitaria, y la capacitación técnica en labores agrícolas.

Al dejar Tierra y Libertad, las comunidades ejidales que formarían después "La Selva" tuvieron que solucionar el problema del transporte por sí mismas. Heriberto Cruz Vera —entonces un joven párroco de Las Margaritas comprometido con la teología de la liberación-ayudó a la nueva organización campesina a adquirir un nuevo camión. Así lo recuerdan los campesinos: "[Se] consiguió comprar un camión de redilas para la comunidad, que, como era de color blanco, le pusimos el nombre-jlógico!--de "El Palomo"'. Genaro Jiménez administró, en el principio, el servicio del transporte que se daba entre las comunidades de la zona. Al camión le correspondía un chofer y su ayudante, aunque muchos de ellos eran irresponsables y "estaban dados al trago". Con las ganancias de pasaje y transporte se daba el mantenimiento al camión y hasta cierto ahorro en beneficio de la "La Selva". Más tarde, en 1986, logró adquirir otro camión y ahorrar suficiente dinero para la caja de UES. La administración rotatoria de los camiones y de la cuenta bancaria, que entonces contaba con \$3 500 000.00, "pasó a manos de miembros integrantes de la unión de [las comu- nidades] Guadalupe Tepeyac y Vicente Guerrero, los cuales, en menos de seis meses, acabaron los ahorros y dejaron inservibles los transportes. No sólo su administración fue mala, también corrupta por desviar fondos colectivos para beneficio personal y, tal vez, como después sospechamos, para el EZLN" (conversación con Genaro Jiménez, trabajo de campo, julio de 2004). ${ }^{12}$

Otra de las situaciones críticas que amenazaron con provocar la salida de los campesinos socios de UES fue el fracaso de la "Unión de Crédito" entre 1982 y 1983. La "Unión de Crédito Agropecuario e Industrial de los Estados de Chiapas y Oaxaca, Pajal Ya Kactic, S.A. de C.V.", constituida en octubre de 1982, estaba conformada por prácticamente todas las uniones ejidales integrantes de la Unión de Uniones, es decir, por las uniones ejidales Pajal, Quiptic, Ejidos de la Selva, Tierra y Libertad, Lucha Campesina y algunas otras de productores oaxaqueños de café (cfr. Legorreta, 1998: 142ss). Esta unión pretendía crear un instrumento económico de financiamiento agrario propio, el cual resultó para los participantes, según el Ing. René Gómez, "muy sofisticado". Ni el conjunto de organizaciones ni sus bases ejidales estaban "preparadas" para el proyecto. "Una de las cosas que empezó a causar [problemas] era la aportación del capital social. Hubo gente que vendió marranos, gallinas, vacas, en fin, lo que pudo para aportar su capital social. De repente algunos amigos dijeron que no era necesario que entregasen dinero, que podían firmar pagarés; lo cual mucha gente hizo comprometiendo su cosecha. Lo feo fue que los que hicieron un esfuerzo vendiendo sus cosas, de repente se enteran que otros sólo firmando documentos [podrían hacer su aportación de capital social]. Y allí se empezó a causar [la] inconformidad" que derivaría, después, en la fractura de la organización, debido también a la incapacidad de los asesores de entenderse política e ideológicamente (entrevista, 11 de agosto de 2003). ${ }^{13}$ Por su parte, los miembros de UES 
se separaron de la Unión de Crédito. Alegaban que los fondos de ahorro estaban siendo malversados. Cuando demandaron a los representantes de la Unión de Crédito para aclarar la situación, éstos al parecer se negaron, lo que ocasionó la salida de UES del proyecto colectivo de financiamiento agropecuario para las uniones ejidales. "[Nos dimos cuanta del mal manejo] por las alteraciones de notas y los apoyos que ellos [los representantes de la unión en cuestión] recibían sólo para ellos. Esto lo denuncian los que no se pusieron de acuerdo con ellos: Arturo Jiménez Hernández y Enrique de la Unión [Quiptic] de Ocosingo. [Eso] fue del año 1983 al de 1984, más o menos. [La división no fue fácil] porque quisieron presionar a nuestros padres. La presión que ellos les hicieron fue de no devolverles su capital que ellos habían aportado en la Unión de Crédito. [Lo que hicieron nuestros padres] fue organizarse más con los compañeros de Ocosingo de la Unión Ejidal Quiptic. Para presionar a los de la Unión de Crédito] pensaron detener los pagos del crédito que ellos habían recibido del banco gestionado por la Unión de Crédito. [No fue fácil esto] porque nos amenazaron con quitarnos nuestro carro de tres toneladas si no pagábamos el crédito". ${ }^{14}$

\section{Aprendizaje de la autonomía organizativa en el mercado cafetalero internacional: INMECAFÉ}

Ya en los primeros años de la mitad de la década de 1980, UES empezó a comercializar café y venderlo a mejor precio para beneficio de los productores a través del Instituto Mexicano del Café, inmeCafé, garantizando, entonces, ingresos regulares a los campesinos ante el deterioro comercial de los cultivos tradicionales como el frijol y el maíz. Creado en 1958, este instituto operaba como un organismo gubernamental que apoyaba el desarrollo de proyectos productivos de café a pequeña escala, a la par que aseguraba la presencia del Estado en los mercados regionales. Entre sus funciones se encontraba financiar la producción a través de créditos, asistencia técnica y regulación del precio cafetalero en el mercado nacional, desplazando así a los acaparadores e intermediarios comerciales.

No obstante, las primeras experiencias de los cafeticultores con el INMECAFÉ no resultaron siempre muy alentadoras, se conjugaban las adversidades de la corrupción burocrática de dicho instituto con la poca experiencia técnica y organizativa de los ejidatarios en la producción de café. A la larga, las movilizaciones de protesta de UES, así como las negociaciones y convenios de su dirigencia con el instituto y la introducción de talleres de asesoría técnica, permitieron mejorar las condiciones de producción, transporte y comercialización del aromático.

Ahora bien, en el contexto de la crisis económica y agropecuaria de la década de 1980, y del desmantelamiento de las instituciones de desarrollo social del Estado bienetarista mexicano en favor de la privatización mercantilista, el INMECAFÉ perdió la importancia que había tenido para el desarrollo técnico, productivo, comercial y social del pequeño productor. ${ }^{15}$ "Su proporción en el mercado bajó de 44 por ciento que mantenía en 1982-1983 a sólo 9,6 por ciento en 1987-1988. Al igual que muchas dependencias estatales en este periodo, sufrió de insuficiencias internas, corrupción y mala administración. Para 1988 el Instituto había acumulado una deuda de aproximadamente noventa millones de dólares" (Harvey, 2000: 188).

La connivencia regular entre intermediarios comerciales y personal de INMECAFÉ obligó a UES, en 1988, a buscar mercados alternativos para lograr vender su producto de manera favorable y no caer de nuevo en el "coyotaje". Así, estableció sus primeros contactos en el mercado internacional del comercio justo. "En la organización [UES] se pensó, entonces, que teníamos que luchar para encontrar un mejor mercado. Don 
Arturo Jiménez Hernández se llevó, entonces, una muestra de tres kilos de café a Europa para que vieran si estaba bien o mal, y lo catalogaran. Y más tarde vino la respuesta de que sí lo iban a comprar a un mejor precio. El INMECAFÉ vio, entonces, que nosotros ya estábamos luchando en el mercado internacional y vino a la comunidad a plantear que siguiéramos con ellos, porque [decía que] el único medio para exportar era el instituto. Por lo regular, nos estaba yendo muy bonito al principio, porque en ese tiempo prácticamente nos daban un anticipo a cuenta de la cosecha" (entrevista colectiva con socios de ues en Cruz del Rosario, 8 de agosto de 2004).

En realidad, la incursión de UES al mercado justo resultó más accidentada de lo que el optimismo de los campesinos, quince años después, deja entrever. El primer intento de comercialización directa realizada por la Unión de Ejidos de la Selva en el mercado justo sucedió en el ciclo 1989-1990, y “resultó una experiencia muy desagradable debido principalmente al comportamiento del mercado. Cuando se acopió café en enero y febrero de 1990, los precios internacionales alcanzaban los doscientos dólares por cien libras. Debido a que en ese momento no se contaban con las cuotas ni los permisos de exportación, la venta no pudo realizarse sino hasta julio, momento en el que los precios habían descendido hasta los ciento sesenta y cinco dólares por libra. Esto significó que los productores que comercializaron por medio de la Unión de la Selva recibieron sólo un setenta por ciento de lo que pagaron los intermediaros en ese año". ${ }^{16}$ Con el fin de acceder a futuros nuevos créditos, los asesores de la organización buscaron convencer a los socios de pagar los préstamos bancarios recibidos para financiar la cosecha. Sin embargo, cuarenta y cinco por ciento de los miembros de La Selva no aceptaron la propuesta y, en consecuencia, abandonaron la organización con gran frustración. "Un indicio del impacto de esa decisión [de pagar los créditos bancarios] fue la caída de la producción en la temporada siguiente. De
1989 a 1990 la UE de la Selva reunió solamente 2890 sacos, en comparación de los 3950 del año anterior" (Harvey, 2000:271).

En 1989 el INMECAFÉ fue cerrado, además en junio de ese año el precio mundial del café sufrió una caída de 50 por ciento. Debido a la sobrevaluación del peso, el crecimiento de la inflación y de los costos de los insumos de producción, el aumento de las exportaciones de café no pudo compensar su caída en los precios mundiales. "A partir de la crisis de 1989 se necesitaron más de tres años de negociaciones y movilizaciones de los grupos de productores para que el gobierno accediera a impulsar un programa de apoyo de emergencia. Con menos ingreso, y al mismo tiempo con una reducción en el crédito, miles de productores fueron incapaces de invertir en sus cultivos. Así, tanto la productividad como el volumen producido del sector social cayeron 35 por ciento entre 1989 y 1993. En promedio, los pequeños productores sufrieron una caída de 70 por ciento en sus ingresos durante el mismo periodo. La mayoría se metió en el círculo vicioso de endeudamiento y pobreza. Imposibilitados para pagar los préstamos debido a la caída de los precios y el ingreso, no resultaron elegibles para la obtención de nuevos préstamos. La acumulación de las deudas de este sector alcanzó aproximadamente los 270 millones de dólares para finales de 1993. En estas condiciones, miles de pequeños productores de Chiapas abandonaron la producción entre 1989 y 1993" (Harvey, 2000: 189s).

Después de más de un año de estancamiento y una palpable pérdida de confianza de muchos de los socios de UES, comenzó un proceso de reorganización basado en talleres de análisis y la programación de actividades en cada comunidad integrante. Asimismo, se formó una comisión encargada de conocer experiencias organizativas de diferentes cooperativas campesinas. Así, por ejemplo, la Unión de Ejidos de la Selva asimiló de organizaciones productores de café — como IXMAL, 
de Tapachula; y UCIRI, Unión de Comunidades Indígenas de la Región Istmo, de Oaxaca — las formas específicas de producción y comercialización para exportar, lo cual contribuyó a su consolidación organizativa. Gracias a este proceso colectivo de reflexión y aprendizaje se iniciaron los cursos de capacitación para los "promotores" de comunidad, el fin era compartir su experiencia en sus ejidos; por ejemplo, el conocimiento de la construcción de terrazas y aboneras o el lavado y secado adecuados para café. "Con una estructura y un proyecto productivo definido nos abocamos a la tarea de constituir distintas figuras asociativas, basadas en las diversas áreas de trabajo que requiere la caficultora, como son la comercialización, la asistencia técnica, la producción y la transformación para ejecutar proyectos de desarrollo económico". ${ }^{17}$

La transacción comercial entre los productores y los consumidores, facilitada por el circuito de comercio justo internacional del sistema Max Havelaar, ocasionó nuevos retos para los socios de UES. El primero fue, sin duda, la garantía en la calidad de café. La inyección de recursos que trajo la sociedad con los compradores del comercio justo pudo utilizarse para el mejoramiento de los cafetales y el giro a la producción orgánica en 1992. Tres años más tarde, el programa de producción orgánica ya se había establecido plenamente y resultó un éxito mercantil de UES. Con este antecedente se logró la certificación de las plantaciones de los socios de UES por parte de la Asociación Internacional de Cultivos Orgánicos y, más tarde, se obtuvo la certificación de la asociación alemana Naturland.

De hecho, con su ingreso al mercado justo, UES había dejado atrás el corsé programático anticapitalista de sus inicios maoístas y estaba incursionando en el terreno de la competencia mercantil en el ámbito internacional como una empresa social de pequeños productores de café. Esto supuso, en definitiva, adoptar estándares empresariales modernos y asumir las realidades de la competencia en el mercado internacional sin "anteojeras" ideológicas con el objetivo de hacer viable el proyecto de los campesinos tojolabales. No obstante, los aspectos sociales del proyecto de UES no se olvidaron. De hecho, su situación más estable en el mercado permitió atender las necesidades y demandas sociales de sus socios. De este modo se fomentaron programas para mejorar y diversificar la producción de cultivos de autoconsumo, así como la gestión de construcción de viviendas, la ampliación de los servicios de salud y educación, y la construcción de infraestructura y equipamiento comunitario. En fin, UES siguió interesada en el desarrollo comunitario y el mejoramiento de los ingresos de sus socios como uno de los principios esenciales de su organización. Esta política social se sostiene a través del mejoramiento de la calidad de la producción y la comercialización, la diversificación de los clientes en Europa, Estados Unidos y Canadá, y la creación en 1995 de una cadena de cafeterías conocida como "El Café de la Selva". "[En efecto,] valiéndose de un sistema bien estructurado de franquicias ha logrado abrir cafeterías en cada vez más ciudades, otorgando a nuestra organización, como logro más importante, la posibilidad de vender una parte importante de su producción en el mercado nacional, reduciendo así la dependencia de las exportaciones y sus fluctuaciones. La puesta en marcha de estas líneas de acción ha permitido ubicarnos en una situación comercial más estable, a pesar de la variación de los precios de café [, y que] en la situación de los últimos meses, en que los precios han caído más del 50 por ciento debido a la especulación financiera y a la sobreproducción mundial, nos esté llevando al límite. Desde el ciclo 1996-1997 80 por ciento del volumen de café comercializado por la Unión de la Selva se ha realizado en condiciones similares a las del comercio justo, gracias a los acuerdos a largo plazo que se han establecido con pequeñas empresas o bien por contratos definidos a partir de la calidad del café que hemos logrado producir". ${ }^{18}$ 
Hoy día, el reto empresarial de "La Selva" consiste en asegurar su posición en el mercado de café de acuerdo con principios de productividad, calidad y sustentabilidad. Esto implica un giro de concepción organizacional: pasar de "la cultura del lamento y el peticionismo" a otra que implique una "alianza" estratégica con el mercado y las instituciones públicas, con base en el apoyo tecnológico, financiero y de asesoría técnica para la producción y la comercialización, sin perder con ello su autonomía ni orientación social. Esta nueva "concepción empresarial" de La Selva surge como respuesta a las condiciones poco propicias del entorno económico — bajos precios del café, disminución de la producción, caída del ingreso de los campesinos, emigración del campo, cambio en el patrón de consumo de café en el ámbito mundial-, de tal suerte que su adaptación al mercado cafetalero del comercio justo global le permita brindar nuevas oportunidades rentables de desarrollo ecológico sustentable, comunitario y familiar a sus socios. Junto con otras organizaciones campesinas, UES se encuentra buscando, pues, nuevos esquemas que vinculen, de manera virtuosa, comercialización, transformación y producción de café y otros productos básicos de los pequeños productores campesinos. ${ }^{19}$

\section{La tormenta zapatista}

Igual que para otras organizaciones campesinas de la región, la formación del EZLN y el levantamiento insurgente de 1994 sometieron a UES a una nueva crisis política. En 1994 buena parte de las comunidades asociadas en la región de la selva a UES abandonaron la organización y se incorporaron al EZLN. Así sucedió, "no porque nos peleáramos, sino porque como algunas de ellas ya estaban metidas en el movimiento armado y nosotros no lo sabíamos, pues, ya no teníamos nada que hacer. Ésta fue una separación interna de la organización, nos desmembramos, pero no fue pleito [entre nosotros, sino que] cada quien agarró su camino. Así, más o menos la mitad se quedó con La Selva y la otra se fue al EZ, como fue el caso de Vicente Guerrero, San Juan Bautista, Guadalupe Tepeyac, La Realidad, San Marcos, Benito Juárez, Flor del Río, y otras más" (entrevista con Genaro Jiménez, líder de UES, 9 de agosto de 2003).

En cambio, los zapatistas ex miembros de La Selva abrigaban otra percepción de la unión ejidal y los resultados de su lucha; en efecto, rompieron con la Unión y se integraron como bases de apoyo del EZLN por el desencanto ante los resultados obtenidos tras largos años de lucha civil. Los ahora rebeldes no veían entonces en UES sólo un instrumento económico para maximizar las ganancias de su producción cafetalera, sino además como un medio para obtener reivindicaciones políticas y de justicia social. Justo porque en los últimos años habían aprendido la gramática elemental de la organización y movilización políticas dentro de la confederación de las comunidades republicanas de masas, comprendieron el valor de actuar en concierto y percibieron las enormes posibilidades que ello abría para inducir, a partir de sus propias fuerzas, el mejoramiento de sus condiciones de vida. "En vez de que nos beneficiara [la cooperación organizada en UES] vimos que nos estaban explotando, porque todos los [gastos] de los que están viajando [para asistir a las reuniones de la organización] tenemos que reponerlo con un día de trabajo, pagar todos los pasajes y hacer toda la cooperación, que es una chinga. Todo era muy difícil y caro [en ese entonces]; y no vimos nada de beneficio económico. Y es que no hubo fuerza [en UES], porque es civil [la organización y su lucha]. [Por esta razón] no nos escuchó el gobierno. [Además], antes era muy peligroso [participar en las organizaciones campesinas] por los pinches ricos, porque si hablas en contra de ellos te fusilan y persiguen" (entrevista colectiva con zapatistas de La Realidad Trinidad, 1 de febrero de 2004). Paradójicamente, los éxitos de la organización 
campesina resultaron, a la larga, causas de su propia debilidad. Tan es así que sus logros, si bien significativos desde la perspectiva de los campesinos involucrados, tenían efectos y consecuencias más bien locales. Al constituirse como un actor colectivo empezaba a modificar la figuración de poder local y regional, pero sin tener una capacidad verdadera de influir en el ámbito estatal y, mucho menos, nacional. A pesar de ello, los campesinos organizados carecían del poder de modificar las políticas nacionales agropecuarias y, mucho menos, la lógica de los mercados internacionales. Así, pues, los inconformes con los logros colectivos imputaron dicha impotencia a la nula voluntad política de los gobiernos y a un supuesto doble juego de los asesores y las organizaciones campesinas. Pero la frustración contenida de los campesinos en relación con los resultados de la unión ejidal sólo se desencadenaría como rechazo a las organizaciones campesinas "civiles" mediante la infiltración y el trabajo ideológico de los guerrilleros del Ejército Zapatista de Liberación Nacional entre las comunidades, los catequistas y los líderes de las organizaciones. En otras palabras, antes de la labor propagandística del EZLN, los campesinos no tenían más opciones realistas que cooperar con las organizaciones campesinas; por tanto, sólo cuando reciben la "oferta" de la "vía armada" para resolver, de una vezy para siempre, sus añejos problemas, fue que su frustración se desencadenó y manifestó en repudio hacia las organizaciones campesinas y los métodos legales de lucha. "La Unión [de Ejidos de la Selva] nada más se ocupa de la producción [de café], pero cuando surgen los problemas [mayores], éstos se resuelven [sólo] con la autoridad [municipal]. [En realidad.] la organización está manejada por el gobierno, no es independiente. El gobierno tiene el control [sobre ella] y compra a la gente [es decir, a los delegados y asesores de la organización]. Nuestra vida no cambió en nada [participando en la Unión], no hubo beneficio para la comunidad, no hubo salud ni escuela" (entrevista colectiva con zapatistas de San José La Nueva Esperanza, 27 de enero de 2004).

Tras la insurrección armada la base social de UES fue sometida a la presión de los dos ejércitos beligerantes, por lo que tuvieron que abandonar, en muchos casos, sus comunidades y refugiarse en las cabeceras municipales de Las Margaritas y Comitán. "En el conflicto [es decir, el levantamiento zapatista de 1994] fuimos desplazados. Teníamos miedo del ejército y de que tiraran bombas; por eso nos tuvimos que ir a Comitán. Allí estuvimos cuatro meses junto con otros socios de otras comunidades de la UES, en los terrenos del Café Tenam [que incluyen las oficinas y bodegas de UES en Comitán]. Allí recibimos despensas del gobierno y los niños siguieron en sus clases para que no olvidaran la escuela. No todos se desplazaron en Cruz del Rosario, porque algunos en la comunidad ya eran zapatistas. Cuando nos fuimos se quedó nuestra tierra sin trabajar y se perdió el café y el maíz. También perdimos muchos de nuestros animalitos, gallinas y cuches, porque los zapatistas se los quedaron y acabaron. Cuando regresamos sólo nos dieron la mitad de los animales" (conversación con doña Rosalía en Cruz del Rosario, trabajo de campo, julio de 2004). Una vez que las comunidades desplazadas pertenecientes a UES regresan a sus comunidades desafiando el cerco zapatista, recibieron amenazas de los rebeldes en el sentido de que si no se incorporaban al EZLN los matarían. Afortunadamente, las amenazas nunca se concretaron y las dos organizaciones, desde entonces, lograron convivir en relativa paz. Acordaron respetarse entre sí y no entrometerse en los asuntos internos respectivos. Con todo, más tarde, algunos socios de La Selva dejaron la organización "por miedo", porque se empezó a utilizar "el nombre de la Unión de la Selva diciendo que todos éramos ya zapatistas". ${ }^{20}$ No obstante, los grupos prozapatistas difamaron a UES calificándola de "priísta y paramilitar", lo que tuvo consecuencias en la percepción que se tenía de ella en el mercado justo 
internacional, lo que afectó temporalmente sus exportaciones.

Aunque uEs se deslindó del zapatismo y logró acordar con el EZLN el "respeto" mutuo entre las organizaciones, no es menos cierto, como sucede en el caso de otras organizaciones campesinas en la región, que sus miembros reconocen el sentido y el valor de la lucha de los zapatistas. Así reflejan las siguientes palabras: "Pero tampoco estoy en contra de ellos [los zapatistas], porque, aunque como organización [UES] nos afectó [el levantamiento], porque estábamos muy avanzados [en el desarrollo productivo, comercial y organizativo de UES], el movimiento [zapatista] también ayudó muchísimo a resolver muchos problemas agrarios... Así, pues, lo bueno del zapatismo es que defienda y luche por los pobres" (entrevista con Genaro Jiménez, 9 de agosto de 2003).

\section{Otra crisis interna más en UEs: E1 "grupo de los seis" y la creación de la Unión de Ejidos Flor de Cafetal}

Una de las características más constantes entre las organizaciones populares es su baja capacidad de institucionalización y sus tendencias regulares hacia las rupturas organizacionales. Como hemos visto hasta ahora, la historia de uEs está marcada por constantes crisis internas. La más reciente de ellas ha sido una de las más graves, puso a La Selva en una situación en la que su existencia estuvo en juego. El origen de la crisis no fue político, sino administrativo. Con su inserción al mercado cafetalero internacional, La Selva se convirtió en una prometedora empresa social con atractivas posibilidades de crecimiento y generación de dividendos. Para cumplir las exigencias contractuales y las expectativas de los consumidores del mercado justo internacional, la unión ejidal racionalizó sus procesos productivos, lo que también se reflejó en una diferenciación cada vez más importante de la administración y gerencia de la organización del resto de los subsistemas de UES. Esta diferenciación administrativa y gerencial implicó, por supuesto, su profesionalización, por lo que hubo la necesidad de contratar un despacho de Tapachula que se encargara de la contabilidad de la empresa. En 1990 la UES ya estaba inserta en el circuito del comercio justo. Ese mismo año se renovó el consejo de administración de la Unión, entre cuyas funciones están las de velar por el cumplimiento de los requisitos de exportación de café y supervisar la entrega de los recursos a los productores socios. Por supuesto, las actividades del consejo eran reportadas a los miembros de La Selva como una manera de fiscalización y administración transparente. Cuando el periodo de administración de este consejo concluyó tres años después, por alguna razón no se eligió uno nuevo, sino que continuó el mismo en funciones. "Y fue entonces que se perdió la línea de la organización, el consejo nos informó que la organización estaba en quiebra, porque ya tenía varios años que no reportaba su estado financiero ni la situación general de la Unión" (entrevista colectiva con socios de UES en Cruz del Rosario, 8 de agosto de 2004). La noticia fue inesperada y alarmante. Los campesinos asociados no podían creer lo que se les informaba por boca de Antonio, el presidente del consejo de administración. "¿Por qué va estar en quiebra la Unión si nosotros entregamos el café y ellos [los importadores de café en Europa] nos pagan? ¿Dónde está esa quiebra?”, se preguntaban los socios (entrevista colectiva, 8 de agosto de 2004). Por supuesto, empezaron a sospechar que había "una fuga de dinero". Además, les sorprendió enterarse que los compradores de café del comercio justo que hacían supervisiones regulares para comprobar la calidad del proceso productivo del café, dejaran de realizar esta supervisión declarando que desde hace seis años no sabían nada de La Selva y que pensaban que ya había desaparecido la organización. Así las cosas, el presidente del consejo fue sustituido, 
pero antes de ello logró dividir la UES y fundar, también en 1998, una nueva organización, Flor de Cafetal, llevándose consigo a gran parte de la base social de La Selva. “ 'La Selva ya no tiene nada', nos dijo Antonio. 'La Selva ya se acabó, porque ni puede comercializar su café y no tiene nada; en cambio, nosotros sí lo podemos hacer, porque estamos en otra organización que puede exportar café y tenemos a la mayoría de los compañeros'. Así nos traicionó", cuentan los estupefactos miembros restantes de la Unión (entrevista colectiva, 8 de agosto de 2004). Una minoría se quedó en La Selva rumiando cómo había hecho Antonio y su consejo de administración para desviar los fondos de la organización y, entonces, fundar una nueva. En realidad, concluyeron, los reportes de su administración que recibían regularmente eran fraudulentos. Nadie se preocupó, durante esos seis años, en corroborar la información del consejo de manera independiente. La confianza en su propia gente y empleados los arruinó. Antonio y su consejo se pusieron de acuerdo con el despacho de contadores de Tapachula para malversar los fondos y amañar los contratos de exportación, por lo que pudieron presentar a la asamblea de la Unión documentos falsos que nadie fiscalizaba. Los "traidores" - que, como eran seis personas, se les conoce, desde entonces, como "el grupo de los seis" — formaron un despacho contable y ofrecieron sus servicios a UES, previo pago de un aguinaldo de \$100 00000 a cada uno de ellos, para reiniciar sus actividades. Los miembros restantes de la Unión rechazaron la propuesta, "porque era un grupo de puros traidores". Pero antes de que la asamblea de UES se reuniera para tomar el acuerdo de destituir al presidente con su consejo de administración, éstos abandonaron para crear Flor de Cafetal. Como uEs carecía de fondos financieros, se llevaron consigo computadoras, camionetas y el permiso de exportación de café propiedad de UES. "Hasta el edificio de UNCAFESUR fue hipotecado por $\$ 800000.00$, dejándonos la deuda.
Nos destruyeron prácticamente la organización. Lo que sí pudimos asegurar fueron Los Cafés de La Selva, porque los asesores eran los que los tenían registrados, por lo que pudimos evitar que esos cabrones se los quedaran. Cuando perdimos el mercado internacional, los Cafés eran el único lugar en el que pudimos vender nuestro producto. ¡Aquí quedamos desmayadísimos!, porque se nos fue la mayoría [de los socios] y nadie podía decir nada. ¡Tantos años de lucha y venimos a ver que en un momento todo se acabó! ¡Estábamos traumatizados! Poco a poco fuimos recapacitando y vimos que todavía teníamos algunos compañeros, doce aquí en Cruz del Rosario, y otros cuántos en otras comunidades. Así perdimos el mercado internacional y tuvimos que vender nuevamente al coyote" (entrevista colectiva, 8 de agosto de 2004). Los pocos socios de UES nombraron a un nuevo presidente y se envió una comisión a Europa para hablar con los compradores de café e informarles que UES no había desaparecido y que habían sido blanco de un fraude, pero querían seguir trabajando en el mercado de comercio justo y requerían su apoyo. "Ni modo, empezamos de nuevo a luchary a mandar pruebas de café. $\mathrm{Y}$ así nos pusimos de pie de nuevo. Ahora somos 35 socios en Cruz del Rosario" (entrevista colectiva, 8 de agosto de 2004). En 2004 la UES logró colocar su producción de nueva cuenta en el mercado internacional.

\section{MUSA y la ampliación del proyecto social: experiencia organizativa de mujeres}

En medio de estos largos procesos de cambio social al interior de sus comunidades, hombres y mujeres tojolabales están aprendiendo a redefinir sus relaciones sociales. Así lo indica la lucha de las mujeres tojolabales por crear su propia organización: Mujeres de la Unión de la Selva, MUSA, fundada oficialmente en 1998 por iniciativa de algunas de las integrantes de La Unión de Ejidos de la Selva. No obstante, su historia se puede 
rastrear ya en los primeros intentos de las mujeres por organizarse en cuanto tales, al menos, desde 1990. En efecto, fueron ellas mismas las que "sintieron la necesidad de organizarse" para resolver algunos problemas comunes. El primer impulso para abordar tareas colectivas nació del interés de producir el pan que consumían y que, anteriormente, compraban a los comerciantes ambulantes a cambio de café.

Así, "pensamos en qué podíamos trabajar juntas" y solicitaron apoyo a los varones de "La Selva" para gestionar, ante SEDESOL, un proyecto de panadería comunitario, lo cual se consiguió en 1992 con el trabajo y el entusiasmo de 60 mujeres de siete comunidades en las que uEs tenía su base social. Sin embargo, para muchas mujeres su primera experiencia de organización resultó difícil de sostener, lo que, a la larga, implicó que sólo 24 de las asociadas iniciales permanecieran unidas. "Al principio no estábamos acostumbradas a salir de nuestras casas; teníamos problemas para atender a nuestros hijos y esposos. Por eso muchas se fueron desanimando. Para muchas era muy costoso participar en las reuniones. Casi no tenían tiempo de moler el maíz, hacer la tortilla y dejar todo listo [en el hogar]. Entonces, para venir a trabajar una se tenía que levantar desde las cuatro de la mañana y dejar lista la cocina. Y luego salíamos un poco tarde de los cursos que nos daban para aprender [a hornear pan], y nos encontrábamos, entonces, con problemas con nuestros esposos, porque ellos ya habían regresado del trabajo y tenían que esperarnos. Muchos hombres como que no estaban acostumbrados a que su mujer saliera y se quedaran viendo [es decir, cuidando] la casa. No comprendían [eso] y no querían que estuviéramos haciendo otra cosa fuera de la casa. Ahora sí ya nos comprenden un poquito y nos dan permiso de salir" (entrevista colectiva con mujeres de MUSA en Nuevo Momón, 11 de julio de 2004). Después de obtener los recursos para financiar el proyecto de panadería comunitaria, las mujeres gestionaron la compra, tam- bién con la intermediación de SEDESOL, de un molino de maíz con vistas a facilitar las labores de la cocina y obtener, así, más tiempo para sus propios intereses organizativos. Si bien la necesidad de cooperar entre sí tenía una motivación pragmática —aliviar la economía doméstica—, sin embargo también había anhelos más profundos que trascendían la esfera familiar. "Nosotras vimos que nuestros esposos ya estaban organizados [en UES], y pensamos que también sería bueno que nos organizáramos para poder sacar adelante un trabajo, compartir nuestras ideas, nuestras experiencias; porque, cuando estamos solas no compartimos nada. Nos juntamos, pero no platicamos de lo que una necesita. Entendimos, pues, que era importante organizarnos como mujeres" (entrevista colectiva, 11 de julio de 2004).

La iniciativa de construir formas de cooperación extradomésticas surge de las mujeres, aunque no es exclusivamente sólo para ellas, pues también "ayudan” a sus hombres. Más tarde, con la fundación de MUSA, este mismo principio de relación entre los sexos se refrenda. MUSA se creó en relación y colaboración íntima con UEs. Así, lo que las campesinas tojolabales consiguieron, fue la diferenciación de espacios y tareas organizativas en donde ellas mismas pudieran definir las metas que perseguirían, así como los medios para hacerlo. Al principio, las asambleas de mujeres tenían lugar en locales de la propia UES en la cabecera municipal, pero los gastos de transporte eran muy altos y mucha la distancia que recorrer, sobre todo teniendo en cuenta que antes de cada salida a las reuniones tenían que dejar preparadas las labores del hogar, por lo que se percataron de la conveniencia de tener a room for their own, que muy pronto gestionaron otra vez ante SEDESOL. Así, nació la Casa de las Mujeres, en Las Margaritas, cuyas réplicas se esparcieron en cada una de las comunidades que cuenta con miembros de MUSA — las Casas de MUSA — . "Entonces se construyó nuestro propio local y empezamos a buscar quién va a ser la representante de la orga- 
nización; y decidimos formar una directiva, pero no fuera de 'La Selva', sino dentro pero como mujeres. Todas nosotras [discutimos] qué es lo que vamos a hacer — para eso están también la directiva [de MUSA] y la asesora-. Después nos pasan la voz a todas las delegadas y allí resolvemos si está bien o no [la propuesta]. [Así, pues,] no son los hombres los que mandan: nosotras decidimos, nosotras tomamos la palabra y nosotras lo resolvemos" (entrevista colectiva, 11 de julio de 2004).

Siguiendo el patrón de UES, aunque a menor escala, MUSA se conformó con su directiva: presidenta, tesorera, secretaria; sus delegadas comunitarias; su base social, las "socias", y su asesora — la cual es externa y recibe un sueldo por su trabajo—. Aunque la asunción de los roles de la presidenta o las delgadas, por ejemplo, son por periodos definidos, cuatro y dos años, respectivamente. Sin embargo MUSA se encuentra con la dificultad estructural de formar cuadros propios que asuman esta responsabilidad, en vista también del reducido número de asociadas con las que cuenta, alrededor de 150, por lo que muchas de las mujeres que asumen dichos papeles tienen que permanecer en su posición más tiempo de lo estipulado por su reglamento interno. Por supuesto, también cuenta el hecho de que muchas de las socias guardan aprensiones acerca de su capacidad personal para poder ocupar el "cargo", así como hacerlo compatible con las múltiples responsabilidades hogareñas. MUSA realiza, por otro lado, asambleas cada dos meses, donde revisan los asuntos de la asociación y reportan los avances de proyectos en marcha. A ellas asisten dos delegadas por comunidad, es decir, catorce en total más la directiva. Las delegadas se encargan de comunicar a sus compañeras las informaciones, resultados y acuerdos de la asamblea. Ellas son elegidas por las socias de cada comunidad, para lo cual se considera que "sepan leer y sean más inteligentes" que sus compañeras; es decir, que sean personas "que sí estén preparadas para salir fuera del lugar [de la comunidad]" (entrevista colectiva, 11 de julio de 2004).

Aunque MUSA es un proyecto de mujeres para beneficio de ellas, no obstante sería difícil calificarla como una iniciativa feminista, pues los problemas de género y hasta los domésticos quedan marginados dentro de las discusiones de las mujeres como asuntos "privados" que cada quien tiene que resolver al interior de su propia familia. "Hablamos mucho de temas de salud, de bienestar para nuestras familias. Claro que sí hablamos de nuestra relación con los hombres, por ejemplo, que no dejan salir a sus mujeres a trabajar, pero allí ya no nos metemos [a resolver] el problema [particular de cada quien], porque eso es la decisión de cada una, pues ya es la vida ajena fuera [de MUSA]" (entrevista colectiva, 11 de julio de 2004). Y aunque lo privado aún no se politiza, el espacio que están creando las socias de MUSA puede generar dinámicas que redefinan los roles tradicionales de hombres y mujeres y se le reconozca a éstas su valor y dignidad, sobre todo en la generación de mujeres más jóvenes que ahora cuentan con mayores grados de escolaridad y nuevas oportunidades laborales.

A pesar de su escepticismo respecto al cambio de actitudes mentales y relaciones tradicionales entre los géneros, lo cierto es que las participantes de MUSA son, ellas mismas, un ejemplo de los cambios sociales en este ámbito. Así lo demuestra, al menos, el significado que otorgan a su experiencia organizativa: MUSA "sí nos ha servido bastante, porque en la organización se aprende a saber y conocer sobre muchas cosas y a hablar con diferentes personas; antes muchas de nosotras no sabíamos hablar con una persona jy ahora hablamos hasta con el mismo presidente municipal y el gobernador! Ahora tenemos la voz de que sí podemos hablar. [Justo] para eso nos sirve la organización: para aprender nuestro derecho que tenemos como mujeres que somos, porque en la misma Constitución se habla que la mujer tiene derechos, y 
eso es lo que nosotras estamos realizando" (entrevista colectiva, 11 de julio de 2004).

\section{Conclusión}

En el contexto de un sistema político autoritario y excluyente, los objetivos políticos iniciales de UES en la década de 1970, al menos tal y como los entendían sus primeros asesores maoístas — la organización autogestiva de las "masas" para preparar la revolución-, dan cuenta de un proyecto "antisistémico" que entre otras cosas implicó la renuncia a la lucha electoral y a las alianzas con partidos políticos, aunque fuesen de oposición, por temor a que sus dirigencias y burocracias los cooptaran. En efecto, La Selva se constituye en un momento histórico en el que los campesinos buscaban, por un lado, vías alternativas de organización a las que ofrecía el corporativismo oficialista de la Confederación Nacional Campesina; y aprovechaban, por el otro, las políticas agrarias posteriores a la administración del gobierno de Luis Echeverría que promovían la producción y comercialización. De esta forma anhelaban construir, sobre todo, organizaciones independientes, democráticas, representativas de sus intereses y eficientes productiva y comercialmente, cuya escala las pudiera hacer manejables y controlables por sus miembros, evitando así reproducir los viejos vicios de una dirigencia privilegiada y autoritaria y una base social sumisa. Asimismo, a la par de que desarrollaban capacidades para proponer alternativas viables de desarrollo rural, estas organizaciones mantenían una relación crítica y fiscalizadora con los organismos gubernamentales destinados al fomento de las actividades agropecuarias.

Ahora bien, a pesar de su objetivo de crear un poder popular autogestivo "de las masas para las masas" que contribuyera a generar las condiciones objetivas y subjetivas para la revolución, UES no desplegó, empero, su lucha política de manera confrontativa, como sílo harían, por ejemplo, CIOAC o la OCEZ en Chiapas, cuya disidencia combativa las expuso a los embates represivos del gobierno, que incluyeron persecuciones, encarcelamientos, intimidaciones y asesinatos de algunos de sus líderes y miembros de sus bases sociales. En este mismo clima de violencia, las organizaciones campesinas de origen maoísta, como UES o Quiptic, optaron, en cambio, por estrategias de lucha que aprovechaban las divisiones al interior del aparato estatal para lograr el apoyo de grupos reformistas simpatizantes con las luchas populares mediante negociaciones, y así conseguir sus objetivos de movilización sin exponer a sus bases ni dirigencias a la represión gubernamental. El inconveniente mayor de esta estrategia era, sin embargo, la cooptación de sus líderes, como eventualmente sucedería, por ejemplo en 1994, con el presidente de la ARIC-Unión de Uniones, Lázaro Hernández.

Veinticinco años después de su fundación, es decir, en un contexto institucional caracterizado, en mayor o menor grado, por la instauración de una democracia representativa, la UEs ha perdido importancia política en la región, justamente por la misma causa que la hizo, en su momento, políticamente independiente y económicamente exitosa: el rechazo a entablar relaciones con partidos políticos y permitir que sus líderes fueran postulados como candidatos de elección popular. Tal parece que las formas anteriores para salvaguardar su independencia política no son las más adecuadas para las condiciones políticas que hoy existen. En comparación, CIOAC ha aprovechado mejor la transición democrática. En efecto, ya desde sus orígenes esta organización campesina buscó el poder público apoyando a partidos de izquierda; esta experiencia le ha permitido adaptarse mejor que UES a las nuevas instituciones políticas, volviéndose así un aliado del gobierno estatal 2000-2006 y asumiendo, en diferentes municipios incluido el de Las Margaritas desde hace cinco años, el rol de gobierno municipal. 


\section{Región historica de la formación de organizaciones campesinas tojolabales ${ }^{21}$}

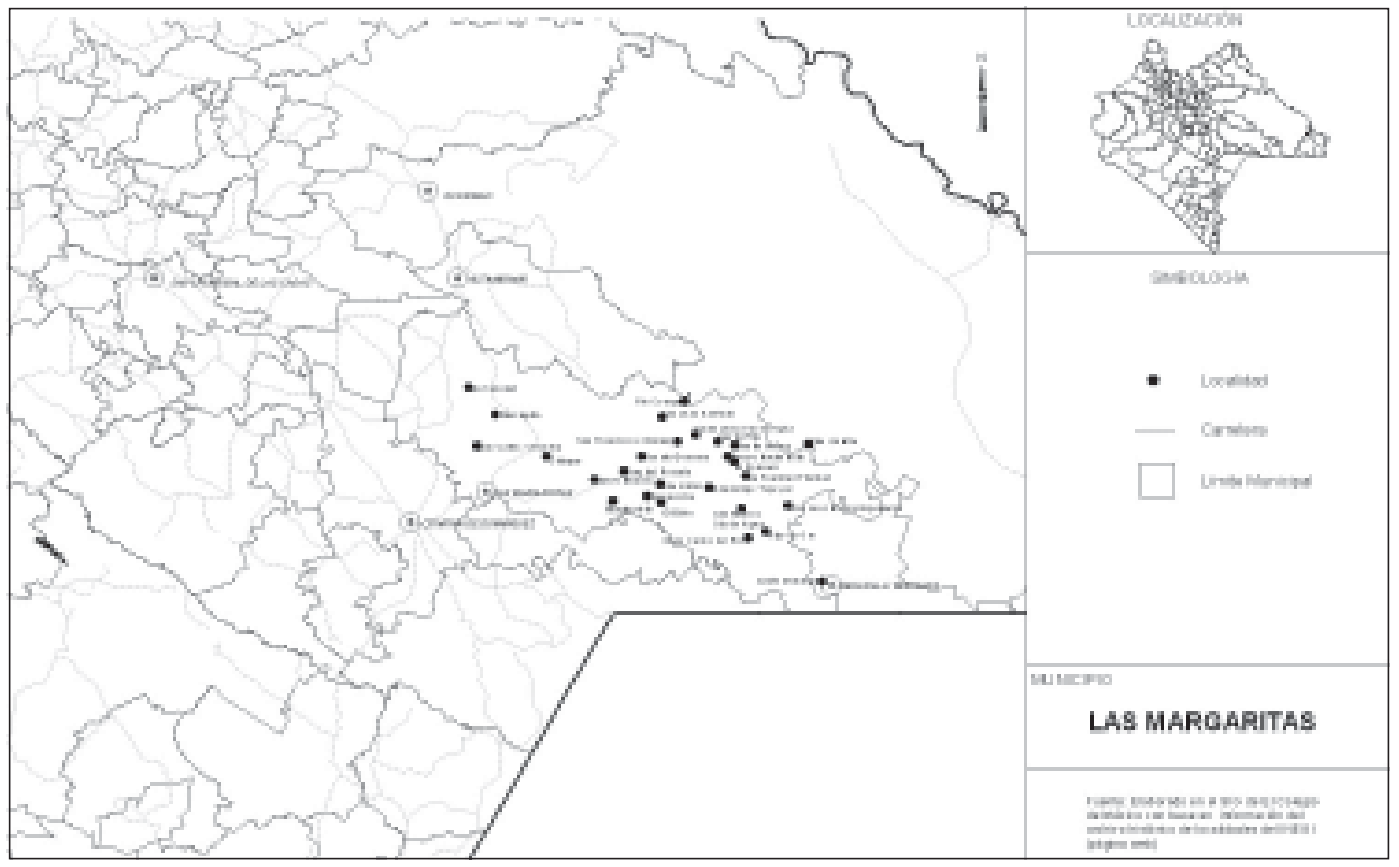

\section{Notas}

${ }^{1}$ Una primera versión de este artículo la presenté como ponencia en el Primer Simposio Internacional Tojolabal, del 21 al 23 de septiembre de 2005 en Comitán, Chiapas (CIESAS-sureste y CISC), bajo el título: "Historias políticas tojolabales. La Unión de Ejidos de la Selva y La Organización de Pueblos Evangélicos Tojolabales".

${ }^{2}$ Sobre el movimiento campesino chiapaneco, véase González Esponda (1989); Harvey (1990 y 2000); Reyes Ramos (1992); Villafuerte et al (1999); Legorreta Díaz (1998); Acosta Chávez (2003); y Montellano García (2001).

${ }^{3}$ Sobre el tema, consúltense Estrada Saavedra (1995, 1997 y 2002).

${ }^{4}$ Sobre las características sociodemográficas de los colonizadores tojolabales en el municipio de Las Margaritas, consúltese Acevedo García (1995); y acerca de los pobladores de la subregiones selváticas en el municipio de Ocosingo, véase Leyva Solano y Ascencio Franco (2002), en particular los capítulos 1 a 4.
${ }^{5}$ Por supuesto, la autonomía de la vida social cotidiana tojolabal es "relativa", porque existe una relación "asimétrica" entre los indígenas y el Estado que está mediada y dominada por la organización política y legal del municipio y el ejido.

${ }^{6}$ Sobre el intercambio social en las fiestas religiosas tojolabales, véase Chavarochette (2005) y Gómez y Pinto (2005).

${ }^{7}$ Para la experiencia de misioneros y catequistas en la Lacandonia de Ocosingo, véase De Vos (2002, en particular el capítulo 6).

${ }^{8}$ Sobre el Congreso Indígena de 1974, consúltese González Esponda (2001), García de León (2002, en particular las páginas 166-177), así como Mestries (1990), este último texto es rico en testimonios de los participantes indígenas en el evento.

${ }^{9}$ Sobre la experiencia de organización social y política en la región selvática de Ocosingo, véase Leyva Solano (1995 y 1998), Leyva Solano y Ascencio Franco (2002), y De Vos (2002, en particular el capítulo 7).

${ }^{10}$ Esta organización fue formada por activistas de Unión del Pueblo, una fracción política de los maoístas. 
${ }^{11}$ Preguntas históricas [de] cómo empezó y cómo seguimos en nuestra lucha, Ejido Cruz del Rosario, Municipio de Las Margaritas, Chiapas, 22 de marzo del 2001.

${ }^{12}$ Cuando Guadalupe Tepeyac y Vicente Guerreo junto con La Realidad Trinidad, San José Nueva Esperanza, El Porvenir y otras comunidades más abandonaron UES algunos años más tarde, no lo hicieron, en realidad, porque 'no les salieran las cuentas', como alegaban -es decir, porque pensaban que UES no les beneficiaba a pesar de la "gran cantidad de trabajo y dinero" que invertían en ella-, sino porque se incorporaron, entre 1991 y 1992, a la Alianza Campesina Independiente Emiliano Zapata y al EZLN sin que los otros socios de Ues estuvieran enterados de sus acciones.

${ }^{13}$ Sobre la crisis que desató el fracaso de la consolidación de la "Unión de Crédito" en Las Cañadas, consúltese Legorreta Díaz (1998: 190ss) y Acosta Chávez (2003: 123ss).

${ }^{14}$ Preguntas históricas [de] cómo emperó y cómo seguimos en nuestra lucha, Ejido Cruz del Rosario, Municipio de Las Margaritas, Chiapas, 22 de marzo de 2001.

${ }^{15}$ Sobre la crisis agropecuaria de las últimas tres décadas, consúltese Villafuerte et al (1998), Villafuerte et al (1999, en particular los capítulos 2 y 3), así como Harvey (1998).

${ }^{16}$ Unión de Ejidos de la Selva, Memoria desde el cafetal, DVD producido por la UES (s/f).

${ }^{17}$ Unión de Ejidos de la Selva, Memoria desde el cafetal, DVD producido por la UES (s/f).

${ }^{18}$ Unión de Ejidos de la Selva, Memoria desde el cafetal, DVD producido por la UEs (s/f).

${ }^{19}$ Sobre el tema, véase la revista Café y sociedad, números 17 (2003) y 25 (2003). En el año 2002, uEs fue acreedora del premio New Ventures 2002 otorgado por el World Resources Institute, que reconoce proyectos empresariales caracterizados por enfatizar de manera plena el desarrollo social, sustentable y empresarial. Así, La Selva fue galardonada "como una de las propuestas de negocios con responsabilidad social y ecológica más sólida de toda América". Caféy sociedad, número 15, 2002, p. 16.

${ }^{20}$ Preguntas históricas [de] cómo empezó y cómo seguimos en nuestra lucha, Ejido Cruz del Rosario, Municipio de Las Margaritas, Chiapas, 22 de marzo del 2001.

${ }^{21}$ Debido al proceso de remunicipalización de 1999 en Chiapas, el ejido Santo Domingo se incorporó al municipio Maravilla Tenejapa.

\section{Bibliografía}

Acevedo García, Marina, 1995, "Margaritas: una experiencia de frontera", en Guillén, Diana (coord.), Chiapas: una modernidad inconclusa, Instituto Mora, México.

Acosta Chávez, Marcela, 2003, "La Quiptic Ta Lecubtesel: autonomía y acción colectiva”, Nueva Antropología, vol. XIX, núm. 63, pp. 115-136.

Chavarochette, Carine, 2005, "Romería de los tojolabales a San Mateo Ixtatán. Un ritual agrícola o cómo las relaciones interétnicas participan en la estructuración de la etnicidad tojolabal", ponencia presentada en el Primer Simposio Internacional Tojolabal, del 21 al 23 de septiembre en Comitán, Chiapas (CIESAS-sureste y CISC).

De Vos, Jan, 2002, Una tierra para sembrar sueños. Historia reciente de la Selva Lacandona, 1950-2002, FCE- CIESAS, México.

Estrada Saavedra, Marco, 1995, Participación politica y actores colectivos, Plaza y Valdés y Universidad Iberoamericana, $2^{\mathrm{a}}$ edición.

—, 1997, “¿Es reformable la teoría de los actores colectivos?”, Revista Mexicana de Sociología, vol. 59, núm. 3, jul-sept, pp. 55-79.

—, 2002, Die deliberative Rationalität des Politischen. Eine Interpretation der Urteilslehre Hannah Arendts, Königshausen \& Neumann, Würzburg, Alemania.

_, 2003, "Für eine neue Welt, eine neue Gemienschaft. Die Erfahrung der Tojolabales bei der Urwaldkolonisierung in Chiapas", en Ethnoscripts, Jahrgang 5, Heft 2, Institut für Ethnologie der Universität Hamburg, pp. 34-52.

—, 2004, "Construyendo el reino de Dios en la tierra: pastoral y catequesis en las Cañadas Tojolabales de la Selva Lacandona (1960-1980)", en Sociológica, UAM-A, año 19, número 55, pp. 199-242.

—, 2005, "Republicanismo en la Selva Lacandona: historia de la constitución de las organizaciones campesinas en las Cañadas Tojolabales (1975-1990)", Estudios Sociológicos, vol. XXIII, núm. 69, septiembre-diciembre, pp.767-806.

García de León, Antonio, 2002, Fronteras interiores. Chiapas: una modernidadparticular, Océano, México.

Gómez, Antonio y Pinto, Delhi Marcela, 2005, "La romería: actividad religiosa en decadencia", ponencia presentada en el Primer Simposio Internacional Tojolabal, del 21 al 23 de septiembre de 2005 en Comitán, Chiapas (CIESASsureste y CISC). 
González Esponda, Juan, 1989, "Movimiento campesino chiapaneco 1974-1984", tesis de licenciatura en economía, uNACH, San Cristóbal de Las Casas.

—, Movimiento campesino, "Del Congreso Indígena a la insurrección zapatista", en Gall, Olivia (coordinadora), 2001, Chiapas: sociedad, economía, interculturalidad y política, uNAM-CEIICH, México.

Harvey, Neil, 1990, "La lucha por la tierra en Chiapas: estrategias del movimiento campesino", en Zermeño, Sergio y Aurelio Cuevas (coordinadores), Movimientos sociales en México, unam, México.

—, 1998, "Rebelión en Chiapas: reformas rurales, radicalismo campesino y los límites del salinismo", en Viqueira, Juan Pedro y Mario Humberto Ruz (eds.), Chiapas. Los rumbos de otra historia, UNAM-CIESAS- CEMCA-UDG, México, $1^{\text {a }}$ reimpresión.

—, 2000, La rebelión de Chiapas. La lucha por la tierra y la democracia, Ediciones Era, México.

Iribarren, Pablo, 2003, Experiencia: Proceso de la Diócesis de San Cristóbal de las Casas. Chiapas. México', Ediciones Piratas, San Cristóbal de Las Casas.

Legorreta Díaz, Ma. del Carmen, 1998, Religión, política y guerrilla en las Cañadas de la Selva Lacandona, Cal y arena, México.

Leyva Solano, Xochitl, 1995, "Militancia político-religiosa e identidad en la Lacandona”, Espiral, vol. I, núm. 2, eneroabril de 1995, pp. 59-88.

—, 1998, "Catequistas, misioneros y tradiciones en Las Cañadas", en Viqueira, Juan Pedro y Ruz, Mario Humberto (eds.), Chiapas. Los rumbos de otra historia, UNAM, CIESAS, CEMCA, UDG, México, $1^{\text {a }}$ reimpresión.

Leyva Solano, Xóchitl y Ascencio Franco, Gabriel, 2002, Lacandonia al filo del agua, FCE-CIESAS-UNAM, $2^{\mathrm{a}}$ edic., México.

Mestries, Francis, 1990, “Testimonios del Congreso Indígena de San Cristóbal de las Casas. Octubre de 1974”, en Moguel, Julio (coordinador del tomo), Historia de la cuestión agraria mexicana. Los tiempos de la crisis 1970-1982, tomo 9, segunda parte, Siglo XXI y СеHAM, México.

Montellano García, Angélica, 2001, "Organizaciones campesinas y corporativismo estatal: la ARIC y la CIOAC en Chiapas", tesis de maestría en estudios latinoamericanos, UAM.
Reyes Ramos, María Eugenia, 1992, El reparto de tierras y la política agraria en Chiapas 1914-1988, uNAM-CIHMECH, México.

Ruz, Mario Humberto (editor), 1986, Los legítimos hombres. Aproximación antropológica al grupo Tojolabal, volumen IV, UNAM, México.

-, (editor), 1990, Los legítimos hombres. Aproximación antropológica al grupo Tojolabal, volumen I y II, UNAM, México.

Van der Haar, Gemma, 2001, Gaining ground. Land reform ant the constitution of community in the Tojolabal Highlands of Chiapas, Mexico, Thala Latin America Series, Amsterdam.

Villafuerte Solís, Daniel y Ma. del Carmen García Aguilar, 1998, "El campo chiapaneco en la encrucijada neoliberal", en Reyes Ramos, María Eugenia, Reyna Moguel Viveros y Gemma van der Haar (coordinadoras), Espacios disputados: transformaciones rurales en Chiapas, UAM -Xochimilco y El Colegio de la Frontera Sur, México.

Villafuerte Solís, Daniel, et al, 1999, La tierra en Chiapas. Viejos problemas nuevos, Plaza y Valdés, UNICACH, México.

\section{Documentos y videos}

Fabila, Alonso, et al., 1959, Estudio acerca del proyecto de colonización en Las Margaritas Chiapas, INI.

López, Aparicio y Demetrio, Erasmo, 1976, Programa de acción indigenista para el sexenio 1976-1982, Centro Coordinados Indigenista de la Región Tojolabal, Las Margaritas.

Preguntas históricas [de] cómo emperó y cómo seguimos en nuestra lucha, Ejido Cruz del Rosario, Municipio de Las Margaritas, Chiapas, 22 de marzo del 2001.

Café y sociedad, revista de la Unión de Ejidos de la Selva, números: 15 (diciembre de 2002), 17 (abril de 2003) y 25 (febrero de 2005).

Unión de Ejidos de la Selva: Memoria desde el cafetal, DVD producido por la UEs (s/f).

INI, Criterios de microrregionalización para la diferenciación de la zona de atención prioritaria, Centro Coordinados Indigenista de la Región Tojolabal, Las Margaritas, 1985. 